\title{
COVID-19: Understanding the Pandemic Emergence, Impact and Infection Prevalence Worldwide
}

\author{
Priyadarshini Dey ${ }^{1}$ (D) S. Vaijayanthimala², Vivek S. Dalvi ${ }^{3}$, Ashu Jain ${ }^{3}$, \\ Deepak Gola4* (D), Medha Bajpai ${ }^{4}$ (D) Randhir K. Bharti ${ }^{(D)}$ and Nitin Chauhan ${ }^{6}$ \\ ${ }^{1}$ Department of Biotechnology, Ramaiah Institute of Technology, Bengaluru - 560 054, India. \\ ${ }^{2}$ Department of Physics, Ramaiah Institute of Technology, Bengaluru - 560 054, India. \\ ${ }^{3}$ Applied Microbiology Laboratory, CRDT, Indian Institute of Technology Delhi, Hauz Khas, New Delhi - 110016 , \\ India. \\ ${ }^{4}$ Department of Biotechnology, Noida Institute of Engineering and Technology, Greater Noida - 201 306, U.P, \\ India. \\ ${ }^{5}$ DS Kothari Post-Doctoral Fellow, University School of Environmental Management, Guru Gobind Singh \\ Indraprastha University, New Delhi - 110078 , India. \\ ${ }^{6}$ Department of Microbiology, Shaheed Rajguru College of Applied Sciences for Women, University of Delhi, \\ New Delhi - 110 007, India.
}

\begin{abstract}
Coronavirus disease (COVID-19) has showed high transmission across the continents due to Severe Acute Respiratory Syndrome Coronavirus-2 (SARS-CoV-2) with total infected cases of around $\sim 44$ million people. This communicable virus that initiated from the Wuhan city of China in the month of December $\mathbf{2 0 2 0}$ has now spread to 189 different countries with 1.1 million fatalities worldwide (till 28 Oct, 2020). The World Health Organization (WHO) declared this outbreak as Public Health Emergency of International Concern in January, 2020. The infection spreads mainly due to contact with infected droplets or fomites, highlighting flu like symptoms initially, which may further progress into severe pneumonia and respiratory failure, often observed in elderly patients with prehistory of other diseases. The diagnosis is based on detection of viral antigen, human antibody and viral gene (RT-PCR). Further, various other diagnostic tools including X-ray, CT-scan are used for imaging purpose, recently artificial intelligence based imaging (contactless scanning) gained popularity. Generally testing of existing drugs (repurposing) and development of new molecules are the main strategies adopted by researchers. However, as per initial findings, various drugs, monoclonal antibody and plasma therapy were found to show effectiveness against COVID-19. Further, many vaccine candidates have entered or will soon enter phase III clinical testing. This disease has further challenged the global economy. Thus, this review uniquely compares the strategies adopted by developed and developing countries worldwide including protective measures like lockdown, continuous testing, utilizing latest tools (artificial intelligence) in curbing this infection spread.
\end{abstract}

Keywords: SARS-CoV-2, COVID-19, pandemic, plasma therapy, artificial intelligence

*Correspondence: deepakgola@gmail.com

(Received: May 26, 2020; accepted: November 09, 2020)

+All authors contributed equally to this work

Citation: Dey P, Vaijayanthimala S, Dalvi VS, et al. COVID-19: Understanding the Pandemic Emergence, Impact and Infection Prevalence Worldwide. J Pure Appl Microbiol. 2020;14(4):2235-2251. doi: 10.22207/JPAM.14.4.02

(C) The Author(s) 2020. Open Access. This article is distributed under the terms of the Creative Commons Attribution 4.0 International License which permits unrestricted use, sharing, distribution, and reproduction in any medium, provided you give appropriate credit to the original author(s) and the source, provide a link to the Creative Commons license, and indicate if changes were made. 


\section{INTRODUCTION}

The world was jolted out of slumber when people in massive numbers succumbed worldwide in a short span of time. These people had pneumonia like symptoms that was first reported in the Wuhan city, Hubei Province of China, in December 2019, highlighting an unknown viral disease ${ }^{1}$. In initial findings, it was observed that the patients shared the common history of visiting the Huanan Sea-Food Whole Sale Market ${ }^{1-2}$. Further, the patients were also identified with no exposure to the Huanan market, clearly highlighting the human to human transmission of the disease ${ }^{3}$. Later, the Chinese Center for Disease Control and Prevention (CDC) and Chinese health authorities identified new coronavirus responsible for the outbreak of pneumonia like disease in Wuhan, China ${ }^{4}$.

The disease is officially named as Corona virus disease-2019 (COVID-19). At present, the virus is referred as the severe acute respiratory syndrome coronavirus-2 (SARS-CoV-2). The virus has been isolated and its genome was sequenced ${ }^{5,6}$. COVID-19 has already been declared as the Public Health Emergency of International Concern ${ }^{7}$. At present more than 44 million confirmed cases were reported in 189 different countries with over 1.1 million fatalities globally as accessed from "Coronavirus COVID-19 Global Cases by the Center for Systems Science and Engineering (CSSE) at Johns Hopkins University (JHU)," 2020. For diagnosis, WHO has recommended the use of RT-PCR for suspected COVID-19 patients9. Till date, there is no vaccine or drug discovered for the treatment of COVID-19. However, several vaccines and drugs are under clinical trials $\mathbf{s}^{10,11}$.

Since such infection multiplies as a result of grouping of relating multiscale (local to global) and multispeed (rapid and slow) changes in human as well as in natural systems ${ }^{12}$. Therefore, every country is working dynamically and aggressively to prevent the proliferation of this emerging infection of COVID-19 at local and global ways. Preventive measures such as rapid testing of suspects for infection and quarantine them and imposition of lockdown at the epicentres of infections.

Further, the global outbreak of COVID-19, will not only affect the health of the people, but will also affect the overall economy of the country in terms of Gross Domestic Product
(GDP). According to Richard Kozul-Wright, Director, Division on Globalization and Development Strategies at United Nations Conference on Trade and Development (UNCTAD) reported in "The Economic Times" (PTI, 10 March, 2020) indicated that COVID-19 may wipe out approximately one trillion USD from the world economy ${ }^{13}$. According to "The Print" (Nair, 6 April, 2020), former Governor of Reserve Bank of India (RBI) and economist Raghuram Govind Rajan has speculated that COVID-19 pandemic would plunge India into economic emergency ${ }^{14}$. As per the recorded data, the last few months had showed substantial infection growth in the total cases of COVID-19. With such surge in the number of positive COVID-19 cases worldwide, it is tough for any country to maintain their GDPs ${ }^{15}$. Therefore, the only solution to overcome this difficult situation is to devise comprehensive control plan comprising of both prevention and treatment in terms spread of infection.

Several researchers ${ }^{16-22}$ have attempted to compile this pandemic of COVID-19. However, there are no systematic studies related to the effect of different measures taken by the developing countries and developed countries across the continents in tackling and containing this pandemic. The goal of this study is to provide useful and significant points analysed from this sudden emerging pandemic of COVID-19 for policy makers for future pandemic preclusion.

\section{Characteristics features of SARS-Cov-2}

Coronavirus is named as SARS-CoV-2 by International Committee of Taxonomy of Viruses (ICTV). It is identified to be a positive sense single stranded RNA virus (+ssRNA), the viral particle is enveloped with spike glycoproteins on the surface. The overall shape of the virus was observed to be round to oval, highlighting crown like appearance under electron microscope with diameter of 50- $200 \mathrm{~nm}^{4}$. The S1 and S2 subunits constitute to form spike glycoproteins, the viral S1 is used for interaction with host receptor, whereas S2 assist the fusion of cellular and viral membrane ${ }^{10}$. Although pathogenesis of SARS-CoV-2 is not fully understood, but as per Xu et al., (2020) ${ }^{16}$ SARSCoV-2 S-protein supports strong interaction with human angiotensin converting enzyme 2 (ACE2). Reports also indicated that spike protein of SARS-CoV-2 binds ACE2 with more than 10-fold 
increased efficacy than SARS-CoV, suggesting the rapid transmission of COVID-19 ${ }^{17}$. The genome of SARS-CoV-2 was found to be $30 \mathrm{~kb}$ in length with $5^{\prime}$ cap and $3^{\prime}$ poly-A tail structure ${ }^{18}$. Zhang et al., $(2020){ }^{19}$ observed that the Pangolin-CoV is $91.02 \%$ and $90.55 \%$ similar with SARS-CoV-2 and BatCov RaTG13, respectively, at whole genome level. As per study, the S1 protein of Pangolin-CoV is much closely related to SARS-CoV-2 than RaTG13, highlighting the closeness of Pangolin-CoV with SARS-CoV-2.

Further, based on sequence analysis, the SARS-CoV-2 is more distant to MERS-CoV and SARS-CoV with $50 \%$ and $79 \%$ similarity, respectively ${ }^{6}$, Moreover, $96 \%$ similarity of SARSCoV-2 was observed with BatCoV RaTG13 at whole genome level2 ${ }^{20}$. Based on these findings, the probability of bat as the original host of SARSCoV-2 is suggested, although an intermediate host might also be present in the transmission process from bat to human ${ }^{4}$. It has also been suggested previously that SARS and MERS have been passed to civets and camels as an intermediate host before infecting humans ${ }^{21}$.

\section{Comparison of SARS-CoV and SARS-CoV-2}

Novel severe acute respiratory syndrome coronavirus-2 (SARS-CoV-2) became pandemic by the end of March 2020. In contrast to the 2002-2003 SARS-CoV outbreak, which had a higher pathogenicity and lead to higher mortality rates, SARSCoV-2 infection appears to be much more contagious. Moreover, many SARS-CoV-2 infected patients are reported to develop low titre neutralizing antibody and usually suffer prolonged illness, suggesting a more effective SARS-CoV-2 immune surveillance evasion than SARS-CoV. Development of low-titre neutralizing antibody was found in SARS-CoV-2-infected patients leading to prolonged illness which is in contrast to SARSCoV. This suggests a more effective SARS-CoV-2 immune surveillance evasion than SARS-CoV. Receptor recognition is an important determinant of human corona virus infection and pathogenesis. The specific surface protein that provides the entry door in human cells for both SARS-CoV and SARSCoV-2 is angiotensin-converting enzyme 2 (ACE2). The first difference between the two SARS-CoVs is that SARS-CoV-2 receptor-binding domain (RBD) has a higher ACE2-binding affinity, a characteristic which could lead to a more efficient cell entry ${ }^{22}$.
Even though SARS-CoV-2 has a less effective binding, it relies on the host protease activation. To summarise, both SARS-CoV and SARS-CoV-2 use human ACE2 as entry receptor and human proteases as entry activators.

Mechanism of transmission of COVID-19 and its clinical symptoms and manifestations

In a recent review, three important human to human transmission routes of SARS-CoV- 2 was mentioned ${ }^{7}$. These are droplet transmission (spreads by cough and sneeze of infected person), direct contact (spreads by physical contact to the infected surface) and aerosol transmission (when droplet of infected person mixed with air and forms aerosol which by inhalation transmits the virus) as the main routes of virus spread. It has been observed that SARS-CoV-2 can remain viable on variety of different surfaces (plastic, steel and wood) from hours to days and can enter the body through various routes, the main entry points for coronavirus is via nose, mouth and eyes. After entering the body, coronaviruses generally get attached itself to host cell receptors (S-mediated) and delivers its genetic material into cell, further it utilizes the host cell machinery to develop its own copies. The incubation period for the SARS-CoV-2 was estimated for upto 1- 14 days.

The clinical symptoms of COVID-19 are similar to any other flu symptoms i.e., sore throat, myalgia, headache and fever etc. Some other symptoms such as dry cough, breathlessness, and chemosensory dysfunction are also common in COVID-19, few patients have also presented conjunctivitis. General symptoms may subside by the end of week or so, with recovery of patient, however if disease progresses, pneumonia and complete respiratory failure may also occur which leads to death ${ }^{20-22}$. It was also observed that patients in older age with prehistory of other complications like lung disease, diabetes, Parkinson, hypertension, heart disease etc, are more prone to enter the critical health conditions which might lead to death?

\section{Diagnosis of COVID-19 infection}

Research confirm that the virus enters respiratory mucosa and after invasion, it infects cells leading to the production of heightened level of cytokines. The lab examination of COVID-19 positive patients showed higher plasma levels of inflammatory cytokines, IL2, IL7, IL10, IL12, 
MCP1, GCSF, TNF-a and low levels of lymphocytes and W.B.C ${ }^{23,24}$. Further, the chest CT-imaging highlighted multiple small patch shadows initially, which develops into ground glass opacities and infiltration in lungs at later stages ${ }^{4}$. The patients with large opacities normally require oxygen therapy and ventilation assistance ${ }^{23-25}$. Recently Alpowdered automated imaging system has showed contactless scanning workflow which prevents the practitioners and technicians from viral exposure ${ }^{27}$. As per the autopsy report of a patient died of COVID-19, the observation of alveolar damage with cellular fibromyxoid exudates was made ${ }^{26}$.

The molecular tests for the diagnosis of COVID-19 can be performed by taking respiratory samples (sputum, lower respiratory tract secretion, throat swab etc.) of patients. The Real time RT$P C R$ and gene sequencing can be performed for screening the suspected COVID-19 patient ${ }^{4}$, however RT-PCR is most commonly used for confirmation in comparison to gene sequencing. WHO also in its interim guidance ${ }^{9}$ suggested the use of nucleic acid amplification tests (NAAT), RT-PCR to testify the status (positive or negative) of suspected COVID-19 patients? Various diagnostic kits for COVID-19 detection have been developed and in use globally. U.S Food and Drug Administration (FDA) has authorised emergency use of Abbots diagnostic test for detection of SARS-CoV-2. The test gives positive result in just 5 minutes by picking the genetic signatures of SARS-CoV-2 ${ }^{28}$. India's first testing kit for COVID-19 has been developed by a Pune based Indian firm named "My Lab. It has got approval to manufacture and sell their kits in different parts of the country ${ }^{29}$. This test is about a quarter of the cost can be reduced by using indigenous kit which India pays to import the kit from abroad.

Further, in another finding, Li et al., $(2020)^{30}$ have developed a rapid IgG and IgM combined antibody test, highlighting efficient consistency for COVID-19. The antibody test is also important to identify the asymptomatic people who have encountered the virus before. Therefore, the true extend of COVID-19 outbreak can be ascertained using antibody test.

\section{C-reactive protein levels in COVID19}

It is significant that COVID-19 patients who progressed from non-severe to severe cases if they are found with elevated levels of
C-reactive protein. Mild patients with an older age and underlying diseases were more likely to exacerbate. Elevated CRP level could be a valuable marker to predict the possibility of aggravation of non-severe COVID-19 patients, which could help health care workers to identify those patients at an early stage for early treatment. However, a large sample size and multicenter studies are needed in order to confirm these results. Based on a retrospective study, few patients CRP levels were collected, and the diameter of the largest lung lesion was measured in the most severe lung lesion by lung CT scan ${ }^{31}$. Differences in the diameter and CRP levels were compared among the groups of patients. They observed a correlation between CRP levels, lung lesion diameter, and disease severity. Both CRP levels and diameter of the largest lung lesion increased with disease progression. Pathological changes of COVID19 are lung and immune system damage. CT dynamic monitoring may be used to identify the characteristic imaging of lung changes. A 50\% increase in lung X-ray findings within 24 to 48 hours was considered an early warning indicator of impending conversion to critical disease. The CT scan can sometimes predict the prognosis of patients. Study showed that CRP levels and the diameter of the largest lung lesion increased as the disease progressed. CRP levels were positively correlated with lung lesion and disease severity. This suggests that in the early stage of COVID-19, CRP levels could reflect lung lesions and disease severity. Several immune proteins that are associated with neutrophils were found at higher levels in the plasma of people who later became critically ill than in those whose illness did not become severe. A subsequent analysis of health records from about 3,300 people showed that high neutrophil counts were associated with increased COVID-19 mortality. Autopsies have found the virus in organs other than the lungs, including the kidneys, liver, heart and brain, as well as in the blood $^{32}$. We now know that symptoms of COVID-19 can include gastrointestinal, neurological, renal, cardiovascular and other complications ${ }^{33}$.

\section{Covid-19 Immunity}

\section{How long does immunity last?}

Presently, there is no validated immune correlation of protection for SARS-CoV-2, ie, antibody level or another immunological marker 
associated with protection from infection or disease. However, in a study that included 82 confirmed and 58 probable cases of COVID-19 from China, the median duration of IgM detection was 5 days (interquartile range, 3-6), while IgG was detected at a median of 14 days (interquartile range, 10-18) after symptom onset ${ }^{32}$. Since the outbreak is only a few months old, there are no data on long-term immune response. Data from SARS-CoV-1 indicate that titres of IgG and neutralizing antibodies peaked at 4 months after infection, with a subsequent decline though at least 3 years after infection.

\section{Reinfections in COVID}

Virologists suggest, that the severity of COVID varies enormously from person to person, and might vary from infection to infection in the same person. Variables such as the initial dose of virus, possible differences between variants of SARS-CoV-2 and changes in a person's overall health could all affect the severity of a reinfection. Clarifying whether 'immunological memory' affects symptoms during a second infection is crucial, particularly for vaccine development. If symptoms are generally reduced the second time, which suggests the immune system is responding as it should. But if symptoms are consistently worse during a second bout of COVID, the immune system might be making things worse, for example, some cases are worsened by rogue immune responses that damage healthy tissue. People who have experienced this during a first infection might have immune cells that are primed to respond in a disproportionate way again the second time. In contrast the antibodies produced in response to SARS-CoV-2 help, rather than fight, the virus during a second infection. This phenomenon, called antibody-dependent enhancement, is rare but researchers found worrying signs of it while trying to develop vaccines against related coronaviruses, responsible for severe acute respiratory syndrome and Middle East respiratory syndrome ${ }^{34}$.

\section{Reinfection and Vaccine Development}

Traditionally, the vaccines that have been at ease to make are against diseases in which primary infection leads to lasting immunity like measles and rubella. This does not mean that a vaccine against SARS-CoV-2 can't be effective, some vaccines, require 'booster' shots to maintain immunity levels. However, the possibility that vaccines will only reduce symptoms during a second infection, rather than prevent that infection altogether. This could effectively turn vaccinated people into asymptomatic carriers, putting vulnerable populations at risk. For this reason, data has to be screened with more diligence on how much virus people 'shed' when reinfected with SARS-CoV- ${ }^{35}$.

\section{Remedies for COVID-19}

After positive diagnosis, before starting any therapy, isolation of the patient is very necessary to prevent the transmission of disease. Further, by providing adequate hydration and nutrition, the health status of the patient can be sustained. As the specific treatment regimen (antiviral therapy) is underway. As per the global perspective, vaccines are considered to be the best approach to control the spread of this disease. The draft of WHO ("DRAFT landscape of COVID-19 candidate vaccines," $19^{\text {th }}$ October, 2020) highlighted that 44 candidate vaccine types are under clinical evaluation i.e., Inactivated (Sinovac), ChAdOx1-s (University of oxford/Astrazeneca), Adenovirus type 5 vector (Cansino Biologicals Inc. \& Beijing Institute of Biotechnology) and LNPencapsulated mRNA (Modern/NIAID), Inactivated (Bharat Biotech), DNA Plasmid vaccine (Cadila Healthcare Ltd.), and many more are under clinical evaluation, whereas 154 other candidate vaccines are under preclinical evaluation stage ${ }^{36}$.

Two major strategies are adopted scientists i.e., repurposing of existing drug and discovery of new molecule. Many drugs have been proposed in research findings, suggesting effectiveness i.e., lopinavir + ritonavir, chloroquine phosphate, Tocilizumab, Nucleoside analogues, Remdesivir, Immunomodulators (dexamethasone), 3CL proinhibitor, PLP inhibitors and Teicoplanin, a glycopeptide antibiotic. Further, several clinical trials are also studying the potential of antiinflammatory therapeutic protein (IL-6R, IL-1R, TNF-a, IFN- $\psi$ ) $^{36,37}$.

As per report, convalescent plasma showed striking improvement in severely ill patients, the viral load decreases and within 3 days, the improvement in cough, chest pain and shortness of breath was observed. In another study, researchers highlighted the treatment of 
two COVID-19 patients with convalescent plasma infusion and observed favourable outcome in addition to systemic corticosteroid ${ }^{38}$.

Further, as per the agents which can block the binding of viral S-protein with ACE2 can also be developed in near future for effective treatment of COVID-1939. Researchers are also working on a novel approach which involve the use of recombinant human soluble ACE2 which competes with endogenous ACE2 protein and neutralize SARS-CoV-2 upon binding ${ }^{37,40}$. However, more concrete research and clinical trials are necessary to confirm the effectiveness and safety of drugs and vaccines for COVID-19 treatment.

Techniques for early viral infection diagnosis and rapid drug designing using state of art tools and technology

The best cure for viral disease is the prevention of onset of infection, thus diagnosing the infection is of prime importance. State of art technologies such as Clustered RegularlyInterspaced Short Palindromic Repeats (CRISPR) technology, rapid, sensitive and specific diagnostic tools have been developed by leading companies (Sherlock Biosciences and Mammoth Biosciences) in the domain of CRISPR based diagnostics ${ }^{41}$. The method is based on the different CRISPRassociated (Cas) enzymes that are programmed by CRISPR RNAs (crRNAs) or single-guide RNAs (sgRNAs). These enzymes can target all types of nucleic acids from wide spectrum of targets such as virus, bacteria, microRNAs etc. ${ }^{42}$. This inexpensive and rapid assay uses Cas12 effector and targets single-stranded RNAs and DNAs that are amplified by loop-mediated isothermal amplification (LAMP). This assay has a detection limit of 10 copies per $\mu \mathrm{L}$ for the detecting diverse regions of SARS-CoV-2 viral genome (E gene and $\mathrm{N}$ gene) by fluorescence in $\mathbf{4 0}$ minutes from the swab samples of the patients ${ }^{43}$.

Another approach utilizing a nanomaterial-based sensor which is arrayed with multiplexed abilities to detect SARS-CoV-2 from the exhaled breath of the patient. The sensors comprise of different gold nanoparticles (AuNPs) and are linked to the organic ligands which creates varied sensing layer that shrinks or swells on exposure to volatile organic compounds (VOCs) emitted from the virus and its surrounding microenvironment that leads to the variations in the electric resistance. The main advantage of this technique is that there is no requirement of swab sample collection from the patient which is followed by its analysis in the laboratory which is time consuming ${ }^{44}$.

Further utilizing tools such as artificial intelligence, novel drugs have been designed to check the virus. A South Korean based company Deargen, utilizing deep learning model identified key compounds that can combat the corona virus. They designed and modelled the potential drug candidate and came up with atazanavir, the medication used for HIV that can impair the proteins on the SARS-CoV- $2^{45}$. These machine learning tools can study the protein structures and determine its effects on corona virus. In this way, unsuccessful attempts in drug discovery are eliminated. Further, Google has launched DeepMind that has scope for protein structure predictions that are related to corona virus and are open sourced. Pharmacologists can utilize this data for vaccine development ${ }^{46}$.

Actions taken worldwide for curtailing COVID-19

The spread of the outbreak of the novel corona virus SARS-CoV-2 in China which was the epicentre of COVID-19, was studied and it was attributed to the droplet transmission. The chain of transmission was studied from 10 people belonging to 3 families who had dined together at an air-conditioned restaurant on 24 January, 2020 in the city of Guangzhou in Guangdong Province, China. Out of these families, one family, with the index patient who had travelled from the city of Wuhan in Hubei Province, China on 23 January, 2020 where the first case of Covid-19 was reported. The following day, from the index patient, the viral infection was transmitted to other members of his family who had symptomatic onset of cough and fever. Consequently, by 5 February, 2020, 9 members from those 3 families fell ill with COVID-19. 10 other people who had dined at the restaurant were also infected. Thus, this spread of infection was traced from this air-conditioned restaurant in Guangzhou. The infection then spread and advanced to different places across cities and countries ${ }^{47}$.

The researchers further highlighted that the spread of infection was rapid droplet transmission due to the strong air flow from the air conditioner at the restaurant. Large respiratory 
droplets that are greater than $5 \mu \mathrm{m}$ are present in the air for a short time and can travel only short distances that are less than 1 metre ${ }^{48,49}$. Droplets smaller than $5 \mu \mathrm{m}$ persists in the air and travel distances longer than 1 metre $^{50}$. It is thus imperative to highlight the potential measures to be taken at individual level and community level for future pandemic prevention when the vaccine for an infection such as COVID-19 is not available or vaccine development is at its nascent stage $\mathrm{e}^{51}$.

Non pharmaceutical interventions to contain the spread the infection

Extensive screening, testing, quarantine and isolation for suspected and infected people

The Government initiatives involved identification and isolation of patients who had symptoms of infection such as high fever and persistent coughing and have tested positive for viral infection. Strict tracing of contact of the affected patients followed by extensive quarantine. The difference between quarantine and isolation is that quarantine is meant for healthy people who may have been to an affected overseas country or have come in close contact with one who has tested positive for the infection. The goal of quarantine is to restrict the person's movement and look for any flu like symptoms while still living with his/her family or roommates. Whereas isolation is applied to those who are showing symptoms or have tested positive for this infection. The aim of isolation is to stop the affected person from further infecting others before his/her recovery ${ }^{52}$.

Massive scale of testing by rapid test kits for COVID-19 infection has proved to contain this infection. It is important know how that some countries like South Korea had maximum number of infected cases after China in early January 2020 and the most popular South East Asian destination Singapore could contain the COVID-19 virus spread by using aggressive preventive method of testing ${ }^{53}$. In Asian countries like South Korea, total lockdown was not imposed. But the South Korean government was swift in early and rapid testing for COVID-19 cases and promptly isolating these patients. The country kept their health workers safe by minimalizing contact. The countries disease control authority approved the test kit during the initial stage of the disease, thus managing to keep this disease at bay. Similar aggressive testing for positive cases was done by the country of Singapore ${ }^{54}$.

In case of the European countries such as in Germany, there were relatively low fatalities rates when compared to other European countries such as Italy and Spain ${ }^{55,56}$. The reason being Germany adopted early and consistent testing; massive tracking of people afflicted with this virus and their contacts and quarantined them. Germany was quick to report its first case in Bavaria region ${ }^{26}$ and also track its contacts and quarantine them. The countries imposed the fourteen days quarantine period as recommended by WHO for people having visited the affected countries or having any overseas visit on the arrival at the airports.

This mandatory critical period of quarantine needs to be followed, as it would regress infection symptoms so that $95 \%$ of the cases could be isolated. This step would aid in designing intervention strategies to curb the infection as the incubation period depends on the generations of the transmission. The infected cases imported from Wuhan were the first generation. Second generation transmission included infection from non-Wuhan imported as well as from generation one. Third generation infected included infection from second generation. While fourth generation infection included from third generation. Since the incubation time of different transmission generation were not significantly different, hypothesizing that the virus does not quickly adapt to humans ${ }^{57}$. The viral load in COVID-19 cases are higher in early days of infection. Viral shedding-a process where once a virus has infected a person, its progeny starts leaving the host. Some of these are released into the environment that can infect others. Viral shedding of patients with COVID-19 confirmed patients intensified before or on symptom onset ${ }^{58}$. Researchers explained that "virus shedding non-infective patient" implied that viral loads were higher in nasal cavity in early phase of infection when compared to the throat ${ }^{59}$. However, the researcher elaborated that patients could be infectious for as long as symptoms lasted or even till clinical recovery.

Lockdown of the epicentre of infection region

The government's efforts in the containment of a viral outbreak from its outset was done right from stage one onwards by the 
approach of lockdown. The government-imposed lockdown of public places and central hubs during the detection of index patient and during the early stage of infection to check and to control the exponential spread and infection of virus. Lockdown is a situation where as a security measure, isolation or restriction on accessibility to public places is imposed ${ }^{60}$.

In the country of China where this viral infection originated and spiralled and had massive initial infected cases, the Governmental measures like stringent lockdown policy that included restricting movement from and to Wuhan and other cities in the Hubei province ${ }^{61}$. All roads were blocked followed by trains and flights being suspended. This was followed by the people being restricted in their homes and allowed to venture only for emergency purposes. Here, social distancing and lockdown proved to extensively contain the infection. Few researchers reported that during the lockdown period starting from 23 January, 2020 in the Wuhan and Hubei province could reduce the infection cases to $98.9 \%$, and the number of deaths could be decreased by up to $99.3 \%$ till 23 February, 2020. This lockdown was carried out in phases throughout China and was instrumental in slowing and bringing down the confirmed cases of infections per day. Thus, it is learnt that within the eruption of few cases of infection, and after the screening and testing, lockdown should be imposed by the government phase wise. First the epicentre, followed by the whole province and then the entire country ${ }^{60}$.

In the country of Italy, which was among the severely affected region having significant number of deaths in a short span in early March, 2020. The lockdown was imposed relatively late and was forced in the country on 9 March, 2020. The restriction on travel from Wuhan to Italy was delayed. The international flights from Italy to Wuhan directly were banned however the indirect flights were not banned. Also, there was delay in the sealing of its borders. This resulted in the widespread and exponential increase in infection in the region of Italy by asymptomatically infected people that overwhelmed, overstretched and crippled the healthcare system ${ }^{62}$.

It is thus pertinent to note that the timely imposition of lockdown and social distancing by the Government is of prime importance.
The aggressive lockdown action of the Chinese government helped in limiting the number of cases in China which is a developing country with the largest population in the world. Whereas, the delay in lockdown in the affected regions of Lombardy and Emilia-Romagna of the developed country like Italy lead to the COVID-19 virus overpowering the population of these regions and created a catastrophe. Thus, making this country having the maximum mortality rate till 01 April, 2020. Likewise, repercussions of delayed lockdown echoed in the countries of Spain, France and United Kingdom in Europe and in United States of America in North America ${ }^{54}$. While in Asia, Iran seemed to have the worst casualties from this infection ${ }^{63}$.

In the southern hemisphere, in countries like New Zealand, early closure of air travels brought down the disease under control and stringent implementation of lockdown nationwide successfully overcame COVID-19 by following elimination based strategy rather than mitigation based strategy ${ }^{64}$. Whereas this infection in Sao Paulo, the most densely populated city of Brazil, in the Latin American in February, 2020 spread like wildfire after its first detection after its importation from Italy resulting in having the maximum number of cases after USA ${ }^{65}$.

In USA, which is the worst affected country in the world, to gain control over the epidemic transmission of this virus non pharmaceutical measures were tried out. Social distancing, nationwide school closures and cancellation of public gatherings were implemented, which were associated with a $30 \%$ reduction in the transmission rate. However, it increased after the mandatory school suspension resumed and before summer vacation started. Given the uncertainties surrounding the extent of the COVID-19 pandemic across the country, efforts to sustain online learning and remote working in combination with enhanced infection control measures in healthcare settings and nursing homes could aid in mitigating the spread of the virus. As respiratory viruses, including other coronaviruses, are known to respond to seasonal variation, there is a plausibility that increasing temperatures in the summer can reduce the intrinsic transmissibility of the novel coronavirus to some extent. In the context of a novel virus, warmer weather alone is 
unlikely to sufficiently mitigate the transmission rate and interrupt community transmission in the absence of social distancing strategies ${ }^{66}$.

By 17 March, 2020 the outbreak had expanded from several isolated clusters in Washington, New York, and California to all 50 states and the District of Columbia. As the COVID-19 outbreak expanded in the US, overall understanding of this disease increased. However, more evidence is needed, particularly for public health and clinical interventions to successfully prevent and treat infections. On analysis of multiple hospitalized patients, it was found that increased circulating levels of neutrophil activators (G-CSF, IL-8) and neutrophil effectors (RETN, LCN2, HGF, and MMP8) were the hallmarks of critical illness in COVID-19 and that they identified high risk patients upon initial admission to the hospital, prior to the onset of critical illness. One of the largest cohorts of COVID-19 patients till date is that early rises in immature granulocyte and neutrophil counts were associated with increased mortality. These findings represent key advances toward understanding the mechanisms of COVID-19 pathogenesis, developing more accurate prognostic indicators, and most importantly, guiding the next generation of therapeutic strategies for COVID-1935.

Lockdown is a delaying tactic to flatten the curve of infection ${ }^{52}$. However, the flipside of lockdown is that it is not a permanent solution, but only to deaccelerate the spread of infection. A three-week lockdown may be inadequate to prevent resurgence ${ }^{67}$. So, lockdown in phases with periodic relaxation can be suggested to eliminate the risk of resurface of the infection ${ }^{68}$.

\section{Disseminating information regarding the pandemic}

The vital role of WHO is immense in dissemination of the scientific and technical information regarding the pandemic to the public. Further coordinating, networking and holding consultation meetings with the member countries. Also as having meaningful collaboration with various laboratories, national health agencies and various non-governmental for containing the disease $^{69}$.

\section{Public hygiene and sanitization}

Here effective public awareness should be created by distancing oneself in crowd. Usage of standard and recommended masks, N95 that have filtration efficiency of $95 \%$ and maintaining individual sanitization protocols and personal hygiene such as cleaning hands with soaps, hand creams and hand sanitizers ${ }^{70,71}$.

Avoiding to touch one's face with hands and covering one's mouth while sneezing and coughing ${ }^{72}$. If required, there are effective masks such as respiratory face masks coated with copper oxide that has antiviral properties ${ }^{73}$. Scientists numerated how the Japanese have been able to curtail this disease because of the good hygiene practices of the people. The people in general are always wearing masks at public places ${ }^{74}$.

Besides personal hygiene, infection by contaminated fomites or surfaces also plays a role. Fomites comprises of both non-porous and porous objects or surfaces that can be contaminated by pathogenic microorganisms and thus transmitters of infection. During infection, viruses spread through different body secretions such as saliva, blood, urine etc. These secretions contaminate the fomites as well as directly by infected hands or by droplets generated by coughing or sneezing. Once the virus is transferred, there is contact between animate and non-animate surfaces. This virus remains viable on these surfaces for different durations. Thus, these fomites must be disinfected on regular basis ${ }^{75}$.

\section{Epidemic/Pandemic modelling of impact and infection spread}

Here the interactive tools are prepared to model pandemics and utilize decision measures to assess their impacts ${ }^{76-78}$. These can be based on air and road traffic with other regions. Citizen health and age profile to predict potential clusters or hotspots of infection for better management of infection spread.

Digital and technological tracking system of infection

Usage of the latest tools and technologies like the data analytics, Internet of Things (IoT) and Artificial Intelligence (AI) in combating the viral spread ${ }^{79}$. This includes mobile phonebased survey in the populations ${ }^{80}$, geographical tracking and mapping of COVID-19. Also, video surveillance, drones or Unmanned Aerial Vehicles (UAVs) for virus infected people in crowded places can be employed ${ }^{81}$. This could be coupled with face recognition and image processing ${ }^{39}$. Such 
approach would alert people who were previously quarantined. It could be taken up location wise, like people who were quarantined if they go in the vicinity of the people who are non-quarantined, would get a signal. And such people would be advised to visit the doctor.

Further for the safeguard of the doctors in hospitals during pandemic crisis where doctors are exposed to infected patients, with the help of artificial intelligence, thermal sensors could be used that accomplish contact based medical procedures such as measuring body temperature etc. ${ }^{82}$.

\section{Indian Scenario to fight against COVID-19 (a case study)}

India, the largest democracy with enormous population is said to be one of the most vulnerable countries; given its high population density, overburdened public health care infrastructure and high prevalence of non-communicable diseases like diabetes and cardiovascular diseases.

The precedence of the spread of the disease in China and some European countries like Italy, Spain and US gave India an opportunity to learn from the impact of the strategies adopted by these countries for combating COVID-19. Even though, the first person to report positive for COVID-19 was on January 30, 2020 followed by two more being reported a couple of days later, it was only a month later that more number of cases of Corona positive patients started getting reported. India's strategy is summarized in following stages Stage I:

\section{Travel Restrictions, Screening and Quarantine}

During January 2020, the onslaught of the COVID-19 epidemic was limited to China, therefore the first travel restrictions were first imposed for travel to China on January 17, 2020 and later on for other COVID-19 affected countries. Intensive point of entry screening was carried out at all international airports, sea-ports and inland borders for early detection and control of the spread of COVID-19 infection. All travellers from the affected countries were quarantined. A very innovative move adopted by the government of India was to stamp the back of the hands of potential COVID-19 carriers with the words 'homequarantined', for compulsive compliance with the advisory. Indelible ink that washes off by two weeks; which matches the quarantine time period, was used for stamping.

\section{Awareness}

Awareness in the masses for the symptoms of COVID-19, its mode of spread and prevention was very crucial for its control. The government of India made a very important and unique move by exploiting the large number of mobile users in India; 1.2 billion subscribers for a population of 1.3 billion as per Telecom Regulatory Authority of India ${ }^{83}$ all wireless carriers inserted a pre-recorded corona health advisory as a caller tune. This led to increased compliance with the measures to be taken against the spread of the virus.

Stage II: Lock down

As the COVID-19 positive cases were showing an upswing, exercising social distancing became more important to break the chain of spread. On March 22, 2020, the Indian Prime Minister imposed a one day 'Janata Curfew', with a greater stress on social distancing. In market places and banks, chalk circles were drawn about 1 meter apart for implementation of social distancing, while shopping for essentials. The total lockdown for 21 days which started from March 24 mid night was imposed as per the lessons learned from other affected countries. The phase 1 of lockdown was followed by phase 2, 3 and 4. Although the lockdown had serious economic implications; a definite loss in GDP, but it was a justified price to pay for the prevention of spread of the COVID-19 pandemic in India.

Relief measures for the poor during lock down

A relief package of Rs.1.7 lakh crore was announced by the Indian finance minister for helping the people during the coronavirus pandemic through cash transfers and food security under the scheme 'Pradhan mantri Gareeb Kalyan Yojna'.

All medical, paramedical staff and workers engaged in essential services like sanitation have been given substantial medical insurance by the Indian government.

\section{Augmenting the testing, isolation and treatment} capacity

The lockdown had definitely slow down the rise of the coronavirus pandemic, India is augmenting its testing facility by purchase 
of additional Personal Protective Equipment (PPE), COVID-19 test kits and gave permission to some private and national laboratories to test for COVID-19. Several automakers like Maruti, Mahindra and Mahindra, Tata motors and Hyundai have been designated the task of developing additional ventilators. Multipatient ventilators are being developed by DRDO (India) in collaboration with Mahindra and Mahindra. Further, as per recent news (PTI, 29 March, 2020b), DRDO has also developed 5 layered N99 mask with 2 layers of Nano mesh, and complete body suit for medical and paramedical staff to stop the contamination through coronavirus ${ }^{84}$.

India has one of the lowest numbers of doctors (0.8) and hospital beds (0.7) per 1000 people in the world as per The World Bank ${ }^{85}$, already facing impending crisis, but still, India is augmenting its capacity by reserving beds in private hospitals, railway hospitals and Army hospitals for corona positive patients. About thousands non-ac coaches of Indian railways are being prepared as isolation wards. Further, a COVID-19 tracking app 'Aarogya setu' has been made mandatory for all government and private sector employees for enhanced tracking and thereby control of spread of COVID 19.

\section{Coronavirus pandemic and India}

$A$ recent research suggested that due to the specific genetic makeup, Indians are less susceptible to COVID-19 due to the presence of a particular RNA protein. Recently, it was highlighted that BCG vaccination provides protection against coronavirus, therefore a decreased morbidity and mortality of affected patients is reported in India ${ }^{86}$. In India BCG is administered by default to all the children born in India as a part of National Policy.

In a study by Indian Council of Medical Research ${ }^{87}$, projections of coronavirus spread were made based on mathematical modelling, it was observed that the quarantine of symptomatic patients may lower the spread of the coronavirus pandemic by $62 \%$ and the peak number of cases by $89 \%$. The lockdown may impact the spread in a similar fashion. Further, the actual impact of the measures of Indian government can only be verified after pandemic subsides.

Global economic analysis during COVID-19 outbreak

As per the research by RaboResearch, experts predicted the GDP (Gross domestic product) growth to be $1.6 \%$ and $3.2 \%$ in year 2020 and 2021, respectively ${ }^{88}$. However, due to the global outbreak of COVID-19, the researcher readjusted the world economic growth and decreases the same by $0.7 \%$. Fig. 1 illustrates the predicted economic growth of world and different countries by experts, before and after the COVID-19 outbreak.

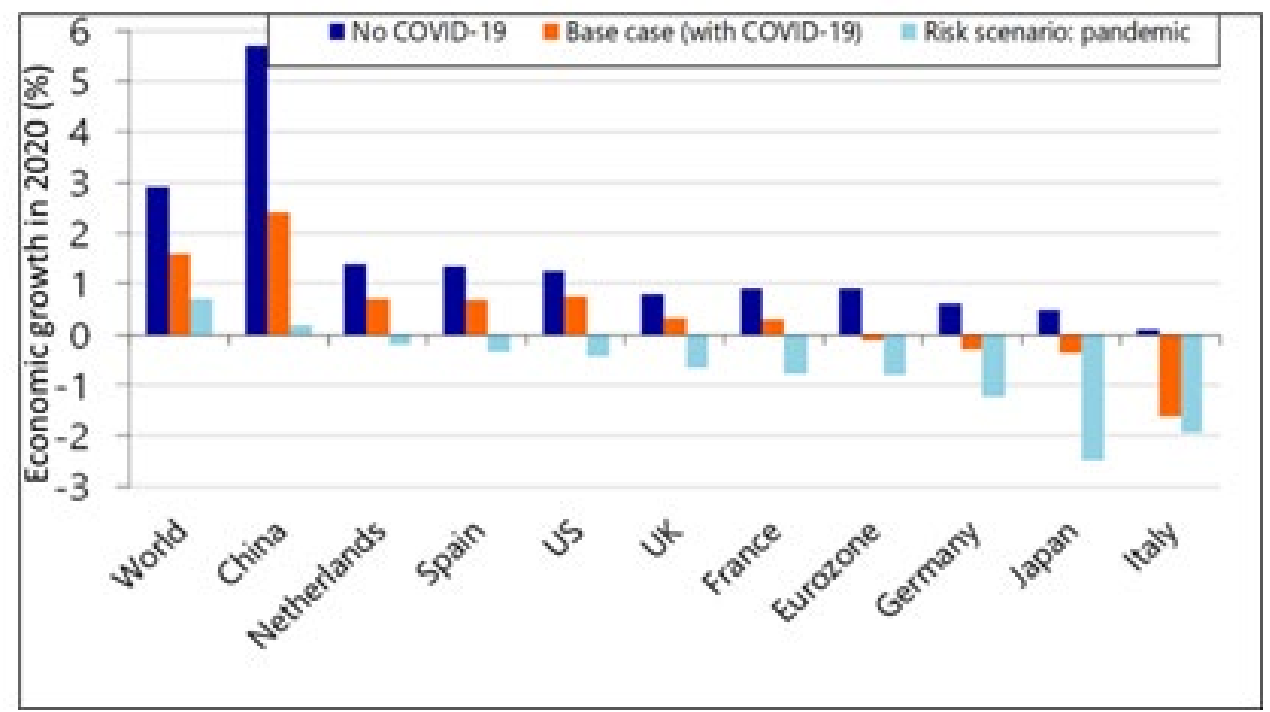

Fig. 1. The economic impact on world and different countries due to COVID-19 outbreak (Source: RaboResearch - Economic Research) 
Moreover, international labour organization predicted that COVID-19 can take upto 25 million jobs worldwide. If we talk in terms of money, the COVID-19 can cost around 1 to 2 trillion US dollar to the world economy. From literature survey it was very much evident that prediction of highly pathogenic coronavirus outbreak was made in January 2019 by a group of researchers from China ${ }^{81}$. The outbreak can cause serious damage to the world economy as per the prediction by multiple financial experts. Experts anticipated that, the global economic impact of COVID-19 will be greater than the SARS epidemic in year 2002-2003, which was also started in China. During 2002-2003, China holds around 9\% of the global, the scenario is very different at present where China holds around $20 \%$ of the global economy ${ }^{88}$. At the end of year 2019, researchers predicted the growth of China to be $5.7 \%$, however due to the COVID-19 outbreak the economic growth of China is readjusted to $2.4 \%$. China plays important role in the global economy and provide multiple industrial goods, food products and agriproduced to countries like India, Italy, Australia, South Korea, Japan, Thailand and Germany etc. The economic growth of many countries is directly dependent on the China. Moreover, with the increased demand of export goods and the source of tourism, China is more interlinked to the various countries as compared to last decade or so. Multiple countries like Italy, India, UK, US, France, etc. announce partial or full lockdown to stop the spreading of COVID-19 at major level as illustrate in Fig. 2. However, this kind of lockdown will cause huge lose to the economic growth of the country.

India announced 40 days lockdown to stop the spreading of COVID-19, however this kind of lockdown may cost around 120 billion USD to Indian economy. As per the survey by REF Racche, COVID-19 can bring down the GDP of Italy by $3 \%$ and $5 \%$ in quarter one and two of 2020, respectively ${ }^{89,90}$. The National Statistical Office (NSO) expected the negative gross domestic growth (GDP) by $23.9 \%$ for Q1FY21. The various factors which will influence the overall economy of the country due to COVID-19 pandemic are as follows

\section{Hours worked}

The lockdown decision by multiple countries will reduce the number of working hour per person. People in the lockdown situation will have limited access to the work.

\section{Private consumption}

The outbreak of COVID-19 will have the negative impact on the consumer and their demand. They might cancel or postpone their order due to limited needs.

Trade

The trades will be in limited amount

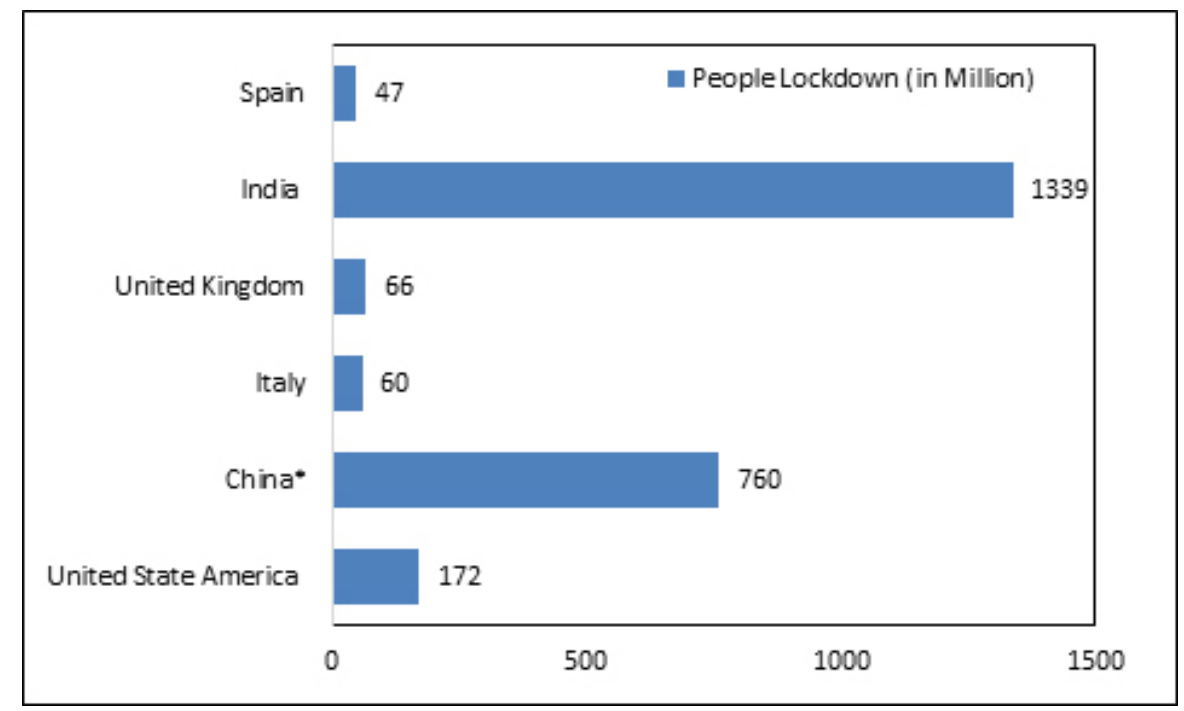

Fig.2. Number of people lockdown in different countries due to COVID-19 outbreak. (*During COVID 19 breakout in China) (Source: Statista, 3 April 2020) ${ }^{76}$ 


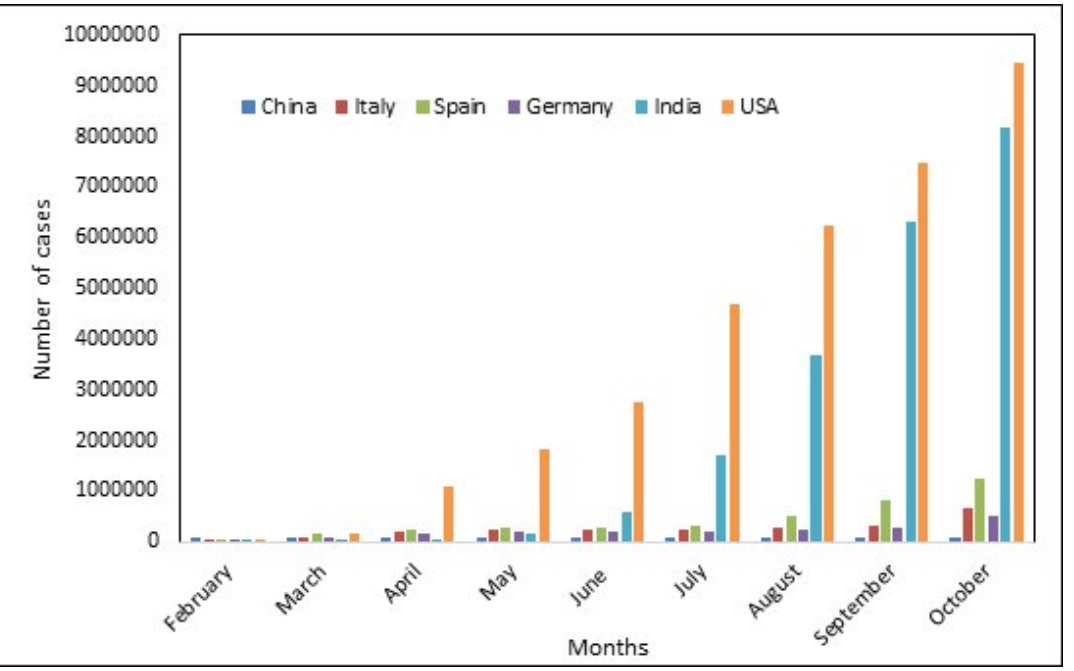

Fig. 3. Number confirmed cases in China, Italy, Spain, Germany, USA and India; as of Oct 2020. (WHO-Novel coronavirus (2019-nCoV). Situation report:1-71)

between COVID-19 infected countries due to the safety concerns as imported items may act as the source of COVID-19. Moreover, trades will become restricted due to safety concerns and new safety norms will be needed.

\section{Government policy}

To ease the pain caused by COVID-19, government will make new supportive policies to stabilize the economy of the country. For example, Indian government announced the package of 1.7 lakh crore to ease the economic need of people according to "The Economic Times" (ET, 27 March, 2020) ${ }^{91}$.

\section{Productivity}

Industrial units experiencing finance difficulties due to low working hour and low consumers demand may reduce the overall production. To overcome their financial loses industries may cut down their budget in each sector and will lower down their man power, hence causing unemployment.

Trend of COVID-19 prevalence in different countries (January-October2020)

Epidemic emergence of SARS-CoV2 virus has threatened the existence of the mankind within short time span of 10 months (Fig. 3). After the first case of SARS-CoV-2 reported in China, the spread of Covid-19 was increased globally and over 49,000,000 patients were tested positive. With such increase in numbers, it is very crucial for major economies to keep the track of development and growth rate. In midFebruary the very first epicentre 'China' managed to control the outbreak of SARS-CoV-2 virus, keeping stagnant growth of new cases with its stringent precautionary measures and treatments methods ${ }^{92}$. But meanwhile, SARS-CoV-2 outburst in major European countries affected majorly Italy, Spain and Germany. The Italy became next epicentre of SARS-CoV-2 after China, majorly spreading in north Italy. The first case of SARSCoV-2 was found on $28^{\text {th }}$ January, 2020 in Italy and just within short span, it crossed the counts of positive cases for up to 824,879 . Similarly, the number of SARS-CoV2 positive cases has crossed $1,365,895$ and 619,116 in Spain and Germany. While USA, unexpectedly has emerged as new epicenter by reaching record SARS-CoV-2 positive number of $9,919,522$. As of today, the scenario has changed completely. European countries like Germany, Italy, and Spain have managed the spread of COVID-19. While, India is setting up to be next epicentre with 8,411,034 positive cases. Recently the government of different countries has opened research grants for the diagnosis and treatment of COVID-19 and many scientist, molecular biologist, biochemist, data scientist and allied field centers are collaborating for its effective control. 


\section{CONCLUSIONS}

With millions of positive cases and fatalities, COVID-19 has greatly impacted the health system and economy and as per current data, around 189 different countries has been affected worldwide. According to the trend of COVID-19 prevalence, there is a continuous increase in the number of cases, with US on top, followed by India and Brazil. With the efforts made by researchers around the globe, various diagnostic kits have been designed to provide accurate results in short time. Some recent report showed contactless imaging systems, designed especially to prevent the spread of COVID-19. As per current update, no treatment or vaccine has been approved specifically for COVID-19, but studies highlighted the effectiveness of many repurposed drugs and few can be used during emergency only. As per the latest draft, 44 candidate vaccine are under clinical evaluations, and 154 other are under pre-evaluation stage. Further, in order to prevent the spread of infection, every country is putting best effort i.e., free distribution of sanitizers and masks (personal protection), rapid screening of suspected cases, their isolation/quarantine, imposition of lockdown and providing essential goods and subsidised food delivery etc. Also new tools such as artificial intelligence seems to come to rescue at this juncture in containing this disease in several ways. In order to assess and manage the pandemic, various interactive tools have been designed to study the impact. In India, a mobile app named 'Aarogya Setu' is used, which not only provide the latest information and also gives the possible hotspots/cluster of infection. Further, the economist throughout the world believes that the outbreak of COVID-19 will affect the global economy and will leads to recession.

\section{ACKNOWLEDGMENTS}

Authors are grateful to the Department of Biotechnology and Department of Physics, Ramaiah Institute of Technology; Department of Biotechnology, Noida Institute of Engineering and Technology; Department of Microbiology, Shaheed Rajguru College of Applied Sciences for Women, University of Delhi and University School of Environmental Management, GGSIPU.

\section{CONFLICT OF INTEREST}

The authors declare that there is no conflict of interest.

\section{AUTHORS' CONTRIBUTION}

All authors listed have made a substantial, direct and intellectual contribution to the work, and approved it for publication.

\section{FUNDING}

None.

\section{DATA AVAILABILITY}

All datasets generated or analyzed during this study are included in the manuscript and/or the Supplementary Files.

\section{ETHICS STATEMENT}

Not applicable.

\section{REFERENCES}

1. Islam A, Ahmed A, Naqvi IH, Parveen S. Emergence of deadly severe acute respiratory syndrome coronavirus-2 during 2019-2020. Virus Disease. 2020: 31(2); 128-136. doi: 10.1007/s13337-020-00575-1

2. Zhu N, Zhang D, Wang W, et al. A Novel Coronavirus from Patients with Pneumonia in China, 2019. N Eng J Med. 2020;382:727-733. doi: 10.1056/ NEJMoa2001017

3. Chan JF-W, Yuan S, Kok K-H, et al. A familial cluster of pneumonia associated with the 2019 novel coronavirus indicating person-to-person transmission: a study of a family cluster. The Lancet Elsevier. 2020;395:514-523. doi: 10.1016/S0140-6736(20)30154-9

4. Deng S-Q, Peng H-J. Characteristics of and Public Health Responses to the Coronavirus Disease 2019 Outbreak in China. J Clin Med. 2020:9. doi: 10.3390/jcm9020575

5. Guo Y-R, Cao Q-D, Hong Z-S, et al. The origin, transmission and clinical therapies on coronavirus disease 2019 (COVID-19) outbreak - an update on the status. Mil Med Res. 2020;7:11. doi: 10.1186/s40779020-00240-0

6. Lu R, Zhao X, Li J, et al. Genomic characterisation and epidemiology of 2019 novel coronavirus: implications for virus origins and receptor binding. The Lancet. Elsevier. 2020;395:565-574. doi: 10.1016/S01406736(20)30251-8

7. Adhikari SP, Meng S, Wu Y-J, et al. Epidemiology, causes, clinical manifestation and diagnosis, prevention and control of coronavirus disease (COVID-19) during the early outbreak period: a scoping review. Infect Dis Poverty. 2020;9:29. doi: 10.1186/s40249-020-00646-x 8. Coronavirus COVID-19 Global Cases by the Center for Systems Science and Engineering (CSSE) at Johns Hopkins University (JHU). John Hopkins, Corona Virus Resource Centre.https://coronavirus.jhu.edu/map. html. Accessed on 24 November,2020. 
9. Laboratory testing for 2019 novel coronavirus (2019$\mathrm{nCoV}$ ) in suspected human cases. World Health Organisation; 2020 Mar p. 1-7. Report No.: WHO/ COVID-19/laboratory/2020.5.

10. Hadi AG, Kadhom M, Hairunisa N, Yousif E, Mohammed SA. A review on COVID-19: origin, spread, symptoms, treatment, and prevention. Biointerface Res Appl Chem. 2020;10:7234-7242. doi: 10.33263/ BRIAC106.72347242

11. Liu C, Zhou Q, Li Y, et al. Research and Development on Therapeutic Agents and Vaccines for COVID-19 and Related Human Coronavirus Diseases. ACS Cent Sci. American Chemical Society. 2020;6:315-331. doi: 10.1021/acscentsci.0c00272

12. Plowright RK, Sokolow SH, Gorman ME, Daszak P, Foley $J E$. Causal inference in disease ecology: investigating ecological drivers of disease emergence. Frontiers in Ecology and the Environment. 2008;6:420-429. doi: 10.1890/070086

13. PTI. (2020, March 10). Coronavirus outbreak could cost global economy up to USD 2 trillion: UNCTAD. The Economic Times. https://economictimes.indiatimes. com

14. Nair R. (2020, April 6). Raghuram Rajan says Covid-19 greatest emergency for Indian economy, Urjit Patel advises caution. The Print.https://theprint.in

15. Makridis, C, Hartley, J. The Cost of COVID-19: A Rough Estimate of the 2020 U.S. GDP (March 22, 2020). Available at SSRN: https://ssrn.com/abstract $=3559139$

16. $\mathrm{Xu} \mathrm{X,} \mathrm{Chen} \mathrm{P,} \mathrm{Wang} \mathrm{J,} \mathrm{et} \mathrm{al.} \mathrm{Evolution} \mathrm{of} \mathrm{the} \mathrm{novel}$ coronavirus from the ongoing Wuhan outbreak and modeling of its spike protein for risk of human transmission. Sci China Life Sci. 2020;63:457-460. doi: 10.1007/s11427-020-1637-5

17. Wrapp D, Wang N, Corbett KS, et al. Cryo-EM structure of the 2019-nCoV spike in the prefusion conformation. Science. American Association for the Advancement of Science; 2020;367:1260-1263. doi: 10.1126/science. abb2507

18. Cascella M, Rajnik M, Cuomo A, Dulebohn SC, Di Napoli R. Features, Evaluation and Treatment Coronavirus (COVID-19). StatPearls. Treasure Island (FL). 2020.

19. Zhang T, Wu Q, Zhang Z. Probable Pangolin Origin of SARS-CoV-2 Associated with the COVID-19 Outbreak. Curr Biol. 2020;30:1346-1351.e2. doi: 10.1016/j. cub.2020.03.022

20. Zhou P, Yang X-L, Wang X-G, et al. A pneumonia outbreak associated with a new coronavirus of probable bat origin. Nature. 2020;579:270-273.

21. Cui J, Li F, Shi Z-L. Origin and evolution of pathogenic coronaviruses. Nat Rev Microbiol. 2019;17:181-192. doi: 10.1038/s41579-018-0118-9

22. Yan R, Zhang Y, Li Y, Xia L, Guo Y, Zhou Q. Structural basis for the recognition of SARS-CoV-2 by full-length human ACE2. Science (New York, N.Y.). 2020;367(6485). 1444-1448. doi: 10.1126/science.abb2762

23. Gao J, Tian Z, Yang X. Breakthrough: Chloroquine phosphate has shown apparent efficacy in treatment of COVID-19 associated pneumonia in clinical studies. Biosci Trends. 2020;14:72-73. doi: 10.5582/ bst.2020.01047

24. Lu H. Drug treatment options for the 2019-new coronavirus (2019-nCoV). Biosci Trends. 2020;14:6971. doi: $10.5582 /$ bst. 2020.01020

25. Baron SA, Devaux C, Colson P, Raoult D, Rolain J-M. Teicoplanin: an alternative drug for the treatment of coronavirus COVID-19? Int J Antimicrob Agents. 2020; 55(4). doi: 10.1016/j.ijantimicag.2020.105944.

26. Spiteri G, Fielding J, Diercke M, et al. First cases of coronavirus disease 2019 (COVID-19) in the WHO European Region, 24 January to 21 February 2020. Euro Surveill. 2020;25(9). doi.org/10.2807/1560-7917. ES.2020.25.9.2000178.

27. Shi F, Wang J, Shi J, et al. Review of artificial intelligence techniques in imaging data acquisition, segmentation and diagnosis for covid-19. IEEE reviews in Biomedical Engineering. 2020 16. doi: 10.1109/ RBME.2020.2987975

28. Harrington A, Cox B, Snowdon J, et al. Comparison of Abbott ID Now and Abbott m2000 methods for the detection of SARS-CoV-2 from nasopharyngeal and nasal swabs from symptomatic patients. $J$ Clin Microbiol. 2020;58(8);e00798-20. doi: 10.1128/ JCM.00798-20

29. Bhatia R, Chaudhary R, Khurana SK, et al. Strengthening of molecular diagnosis of SARS-CoV-2/COVID-19 with a special focus on India. J Pure Appl Microbiol. 2020;14(suppl 1):789-798. doi: 10.22207/JPAM.14. SPL1.16

30. Li X, Geng M, Peng Y, Meng L, Lu S. Molecular immune pathogenesis and diagnosis of COVID-19. Journal of Pharmaceutical Analysis. 2020; 10(2):102-108. https:// doi.org/10.1016/j.jpha.2020.03.001

31. Ling W. C-reactive protein levels in the early stage of COVID-19. Médecine et Maladies Infectieuses. 2020; 50(4):332-334. https://doi.org/10.1016/j. medmal.2020.03.007

32. Puelles VG, Lutgehetmann M, Lindenmeyer MT, et al. Multiorgan and renal tropism of SARS-CoV-2. N Engl J Med. 2020; 383:590-592. https://doi.org/10.1056/ NEJMc2011400

33. Gupta A, Madhavan MV, Sehgal K, et al. Extrapulmonary manifestations of COVID-19. Nature Medicine. 2020;26(7):1017-1032. doi: 10.1038/s41591-0200968-3

34. Ledford $\mathrm{H}$. Evidence lags behind excitement over blood plasma as a coronavirus treatment. Nature. 2020;584:505. doi: 10.1038/d41586-020-02324-2

35. Maxmen A. Why the United States is having a coronavirus data crisis. Nature. 2020;585:13-14. doi: 10.1038/d41586-020-02478-z

36. Tyagi PK, Tyagi S, Kumar A, Ahuja A, Gola D. Contribution of Nanotechnology in the Fight Against COVID-19. Biointerface Research in Applied Chemistry. 2020; 11(1): 8233 - 8241.

37. Twomey JD, Luo S, Dean AQ, Bozza WP, Nalli A, Zhang B. COVID-19 update: The race to therapeutic development. Drug Resistance Updates. 2020:53;100733. doi: 10.1016/j.drup.2020.100733

38. Ahn JY, Sohn Y, Lee SH, et al. Use of Convalescent Plasma Therapy in Two COVID-19 Patients with Acute Respiratory Distress Syndrome in Korea. J Korean Med Sci. 2020; 35(14): e149.

39. Li S, Ning $X, Y u$ L, et al. Multi-angle Head Pose 
Classification when Wearing the Mask for Face Recognition under the COVID-19 Coronavirus Epidemic. In2020 International Conference on High Performance Big Data and Intelligent Systems (HPBD\&IS). IEEE. 2020:1-5. doi: 10.1109/HPBDIS49115.2020.9130585

40. Monteil V, Kwon $\mathrm{H}$, Prado $\mathrm{P}$, et al. Inhibition of SARS-CoV-2 infections in engineered human tissues using clinical-grade soluble human ACE2. Cell. 2020;181(4);905-913. doi: 10.1016/j.cell.2020.04.004

41. Sheridan C. Fast, portable tests come online to curb coronavirus pandemic. Nat Biotechnol. 2020;38:515518. doi: 10.1038/d41587-020-00010-2

42. Morales-Narvaez E, Dincer C. The impact of biosensing in a pandemic outbreak: COVID-19. Biosensors and Bioelectronics. 2020;163:112274. doi: 10.1016/j. bios.2020.112274

43. Broughton JP, Deng X, Yu G, et al. CRISPR-Cas12-based detection of SARS-CoV-2. Nature Biotechnology. 2020:38;870-874. doi: 10.1038/s41587-020-0513-4

44. Shan B, Broza YY, Li W, et al. Multiplexed nanomaterialbased sensor array for detection of COVID-19 in exhaled breath. ACS Nano. 2020;14(9):12125-12132. doi: 10.1021/acsnano.0c05657

45. Beck BR, Shin B, Choi Y, Park S, Kang K. Predicting commercially available antiviral drugs that may act on the novel coronavirus (SARS-CoV-2) through a drug-target interaction deep learning model. Comput Struct Biotechnol J. 2020;18:784-790. doi: 10.1016/j. csbj.2020.03.025

46. Alimadadi A, Aryal S, Manandhar I, Munroe PB, Joe B, Cheng $X$. Artifcial intelligence and machine learning to fight COVID-19. Physiol Genomics.2020.52: 200-202

47. Lu J, Gu J, Li K, Xu C, Su W, Lai Z, et al. COVID-19 Outbreak Associated with Air Conditioning in Restaurant, Guangzhou, China, 2020. Emerg Infect Dis. 2020;26(7):1628-1631

48. Kutter JS, Spronken MI, Fraaij PL, Fouchier RA, Herfst S. Transmission routes of respiratory viruses among humans. Current Opinion in Virology. 2018;28:142151. doi: 10.1016/j.coviro.2018.01.001

49. Pica N, Bouvier NM. Environmental factors affecting the transmission of respiratory viruses. Current Opinion in Virology. 2012;2(1):90-95. doi: 10.1016/j. coviro.2011.12.003

50. Fernstrom A, Goldblatt M. Aerobiology and its role in the transmission of infectious diseases. J Pathogens. 2013;2013. doi: $10.1155 / 2013 / 493960$

51. Ahmed SF, Quadeer AA, McKay MR. Preliminary Identification of Potential Vaccine Targets for the COVID-19 Coronavirus (SARS-CoV-2) Based on SARSCoV Immunological Studies. Viruses. 2020;12. doi: 10.1101/2020.02.03.933226

52. Anderson RM, Heesterbeek $\mathrm{H}$, Klinkenberg D, Hollingsworth TD. How will country-based mitigation measures influence the course of the COVID-19 epidemic? The Lancet. Elsevier. 2020;395:931-934. doi: 10.1016/S0140-6736(20)30567-5

53. Lee VJ, Chiew CJ, Khong WX. Interrupting transmission of COVID-19: lessons from containment efforts in Singapore. J Travel Med. 2020;27(3). doi: 10.1093/ $\mathrm{jtm} / \mathrm{taaa039}$

54. Cohen J, Kupferschmidt K. Countries test tactics in 'war' against COVID-19. Science. American Association for the Advancement of Science; 2020;367:1287-1288. doi: $10.1126 /$ science.367.6484.1287

55. Yuan J, Li M, Lv G, Lu ZK. Monitoring transmissibility and mortality of COVID-19 in Europe. Int J Infect Dis. 2020;95:311-315. doi: 10.1016/j.ijid.2020.03.050

56. Flaxman S, Mishra S, Gandy A, et al. Estimating the effects of non-pharmaceutical interventions on COVID-19 in Europe. Nature. 2020;584(7820):257-261. doi: $10.1038 / \mathrm{s} 41586-020-2405-7$

57. Gao Y, Shi C, Chen Y, Shi P, Liu J,Xiao Y, Shen Y, Chen E.A cluster of the Corona Virus Disease 2019 caused by incubation period transmission in Wuxi, China.Journal of Infection.2020;08:666-670.

58. Singhal, T. A Review of Coronavirus Disease-2019 (COVID-19). Indian J Pediatr. 2020;87(4):281-286. doi: 10.1007/ s12098-020-03263-6

59. Lau H, Khosrawipour V, Kocbach P, et al. The positive impact of lockdown in Wuhan on containing the COVID-19 outbreak in China. Journal of Travel Medicine. 2020;27(3):taaa037. doi: 10.1093/jtm/ taaa037

60. Salzberger B, Gluck T, Ehrenstein B. Successful containment of COVID-19: the WHO-Report on the COVID-19 outbreak in China. Infection. 2020;48:151153. doi: $10.1007 / \mathrm{s} 15010-020-01409-4$

61. Mei C. Policy style, consistency and the effectiveness of the policy mix in China's fight against COVID-19. Policy and Society. 2020; 39:3, 309-325.

62. Pepe E, Bajardi P, Gauvin L et al. COVID-19 outbreak response, a dataset to assess mobility changes in Italy following national lockdown. Sci Data.2020; 7, 230.

63. Takian A, Raoofi A, Kazempour-Ardebili S. COVID-19 battle during the toughest sanctions against Iran. The Lancet. Elsevier. 2020; 395:1035-1036. doi: 10.1016/ S0140-6736(20)30668-1

64. Baker MG, Wilson N, Anglemyer A. Successful Elimination of Covid-19 Transmission in New Zealand. N Engl J Med. 2020;383(8): e56. doi: 10.1056/ NEJMc2025203

65. Candido DDS, Watts A, Abade L, et al. Routes for COVID-19 importation in Brazil. J Travel Med [Internet]. Oxford Academic. 2020; 27 (3); taaa042

66. Dogan B, Jebli MB, Shahzad K, Farooq TH, Shahzad U. Investigating the effects of meteorological parameters on COVID-19: case study of New Jersey, United States. Environmental Research. 2020; 191:110148. doi: 10.1016/j.envres.2020.110148

67. Sarwal R, Sarwal T. Mitigating COVID-19 With Lockdowns: A Possible Exit Strategy. SSRN.2020 doi: 10.2139/ssrn. 3563538

68. de Souza SLT, Batista AM, Caldas IL, larosz KC, Szezech JD. Dynamics of epidemics: Impact of easing restrictions and control of infection spread. Chaos, Solitons \& Fractals.2020; e 110431.

69. Galaz V. Pandemic 2.0: Can information technology help save the planet? Environment: Science and Policy for Sustainable Development. 2009;51(6):20-28. doi: 10.1080/00139150903337225

70. Li Y, Tokura H, Guo YP, et al. Effects of wearing N95 and surgical facemasks on heart rate, thermal stress and subjective sensations. Int Arch Occup Environ Health. 
2005; 78:501-509. doi: 10.1007/s00420-004-0584-4

71. Saunders-Hastings P, Crispo JAG, Sikora L, Krewski D. Effectiveness of personal protective measures in reducing pandemic influenza transmission: A systematic review and meta-analysis. Epidemics. 2017; 20:1-20. doi: 10.1016/j.epidem.2017.04.003

72. Darlenski R, Tsankov N. Covid-19 pandemic and the skin - What should dermatologists know? Clinics in Dermatology. 2020. doi: 10.1016/j. clindermatol.2020.03.012

73. Borkow G, Zhou SS, Page T, Gabbay J. A Novel AntiInfluenza Copper Oxide Containing Respiratory Face Mask. PLoS ONE. 2010;5: 11295. doi: 10.1371/journal. pone.0011295

74. Qian K, Yahara T. Mentality and behavior in COVID-19 emergency status in Japan: Influence of personality, morality and ideology. PloS ONE. 2020;15(7): e0235883. doi: 10.1371/journal.pone. 0235883

75. Boone SA, Gerba CP. Significance of Fomites in the Spread of Respiratory and Enteric Viral Disease. Appl Environ Microbiol. American Society for Microbiology. 2007;73: 1687-1696. doi: 10.1128/AEM.02051-06

76. Muellner U, Fournie G, Muellner P, Ahlstrom C, Pfeiffer DU. epidemix - An interactive multi-model application for teaching and visualizing infectious disease transmission. Epidemics. 2018; 23:49-54. doi: 10.1016/j.epidem.2017.12.003

77. Maciejewski R, Livengood P, Rudolph S, et al. A pandemic influenza modeling and visualization tool. Journal of Visual Languages \& Computing. 2011; 22:268-278. doi: 10.1016/j.jvlc.2011.04.002

78. Wu JT, Leung K, Leung GM. Nowcasting and forecasting the potential domestic and international spread of the 2019-nCoV outbreak originating in Wuhan, China: a modelling study. The Lancet. Elsevier. 2020; 395:689697. doi: 10.1016/S0140-6736(20)30260-9

79. Fitzpatrick F, Doherty A, Lacey G. Using Artificial Intelligence in Infection Prevention. Curr Treat Options Infect Dis. 2020 1-10. doi: 10.1007/s40506-020-002167

80. Rao ASRS, Vazquez JA. Identification of COVID-19 Can be Quicker through Artificial Intelligence framework using a Mobile Phone-Based Survey in the Populations when Cities/Towns Are Under Quarantine. Infection Control \& Hospital Epidemiology. Cambridge University Press; 2020:1-18.

81. Kumar A, Sharma K, Singh H, Naugriya SG, Gill SS, Buyya R. A drone-based networked system and methods for combating coronavirus disease (COVID-19) pandemic. Future Generation Computer Systems. 2020; 115:1-9. doi: 10.1016/j.future.2020.08.046

82. Jeong W, Kim M, Ha J-H, et al. Accurate, hysteresis-free temperature sensor for health monitoring using a magnetic sensor and pristine polymer. RSC Advances. Royal Society of Chemistry. 2019;9: 7885-7889. doi: 10.1039/C8RA10467K

83. The Indian Telecom Services Performance Indicators. https://www.broadcastandcablesat.co.in, Accessed on 24 November, 2020.

84. PTI. (2020, March 29). N99 masks, bodysuit: DRDO's plan to combat coronavirus. The Economic Times. https://economictimes.indiatimes.com

85. World Development Indicators. The World Bank. https://databank.worldbank.org, Accessed on 24 November,2020.

86. Sharma AR, Batra G, Kumar M, et al. BCG as a gamechanger to prevent the infection and severity of COVID-19 pandemic. Allergol Immunopathol. 2020; 48(5):507-517. doi: 10. 1016/j. aller.2020.05.002

87. Mandal S, Bhatnagar T, Arinaminpathy $\mathrm{N}$, et al. Prudent public health intervention strategies to control the coronavirus disease 2019 transmission in India: A mathematical model-based approach. Indian Journal of Medical Research.2020; 151(2): 190-199.

88. Global Economic Outlook: COVID-19 has taken a hold of the global economy [Internet]. RaboResearchEconomic Research. https://research.rabobank.com, Accessed on 24 November,2020.

89. PTI. (2020, March 25). Cost of 21-day lockdown: India to lose Rs 9 lakh crore as people slam doors shut on coronavirus. The Financial Express. https://www. financialexpress.com

90. Italy: forecasted impact of coronavirus on GDP Q1-Q2 2020. Statista. https://www.statista.com, Accessed on 24 November, 2020.

91. ET. (2020, March 27).FM Nirmala Sitharaman announces Rs 1.7 lakh crore relief package for poor. The Economic Times. https://economictimes. indiatimes.com

92. Lai C-C, Shih T-P, Ko W-C, Tang H-J, Hsueh P-R. Severe acute respiratory syndrome coronavirus 2 (SARS-CoV-2) and coronavirus disease-2019 (COVID-19): The epidemic and the challenges. Int J Antimicrob Agents. 2020; 55:105924. doi: 10.1016/j. ijantimicag.2020.105924 